\title{
SOME MECHANISMS OF TACTLE LOCALIZATION REVEALED BY A STUDY OF LEUCOTOMIZED PATIENTS
}

\author{
BY
}

\author{
ALICK ELITHORN, MALCOLM F. PIERCY, and MARGARET A. CROSSKEY \\ From the Neurological Research Unit of the Medical Research Council, and the Psychological \\ Department, National Hospital, Queen Square, London
}

This investigation was undertaken following a suggestion that finger agnosia occurred after prefrontal leucotomy. A preliminary investigation did not reveal the presence of finger agnosia as described by Gerstmann (1924) but confirmed the existence of a post-operative difficulty in localizing tactile stimuli on the fingers. Accordingly, the present investigation was designed with the object of examining the extent and nature of this defect and in the hope that the nature of the errors would reveal something of the mechanism by which normal localization of tactile stimuli occurs.

Although tests of tactile localization are used clinically, and may assist in the diagnosis of cerebral damage, very little is known concerning the neurological and psychological mechanisms mediating the " local sign" of tactile stimuli. The most notable clinical studies are those of Head (1920) who convincingly demonstrated the impairment of tactile localization which may attend parietal lobe dysfunction. Head also studied the restitution of sensory function following section of the radial nerve. His studies of peripheral nerve lesions led him to postulate the famous protopathic-epicritic dichotomy whereby it was claimed that only epicritic nerve fibres mediated local sign, thus reverting in essence to the "doctrine of specific nerve energies". This suggestion has been seriously challenged by Walshe (1942) on theoretical grounds, and Sherrington (1947) has suggested that the essential peripheral basis of tactile local sign might be the distribution of overlapping sensory units. In the case of defects of tactile localization resulting from cerebral injury Head asserted that such defects occurred only as a result of parietal injuries and that, when errors of localization on the fingers occurred, their distribution was consistent with random guessing and provided no evidence for supposing either that errors were more frequent in the case of some positions than others, or that stimuli were erroneously referred more frequently to one site than to another. He refers to a conceptual "schema" of tactile (and proprioceptive) orientation which presumably is either intact or, when impaired by brain damage, impaired in an essentially non-specific way.

Gerstmann has claimed that with some cerebral lesions there is a condition described as finger agnosia in which there is an inability to recognize individual fingers. It is not clear, however, that in these cases there is an impairment of the ability to make a localizing response to stimuli on the affected fingers.

Investigations in this field undertaken by psychologists have been almost exclusively concerned with healthy subjects, and have been devoted largely to testing the relative efficiency of different skin areas and to demonstrating the presence of systematic errors of tactile localization. Thus it has been known for many years that the accuracy of tactile localization depends greatly on the part of the body stimulated. It is also well known that stimuli tend to be displaced towards the nearest joint rather than away from it, and towards the pre- and post-axial borders of the limb. In one of the more important contributions to the subject Spearman (1906) demonstrated many of the factors involved. He showed that when a point on a limb was stimulated the subject tended to refer it in a direction which was dependent on the relative position of the stimulus site to the rest of the body, and, in particular, that the direction in which an error was made was related to the direction in which the stimulated part deviated from its mid-position with reference to the next proximal joint. Some of these results have been confirmed by Hulin (1935), who also showed that when a limb was stimulated in motion then the direction of movement correlated with the direction of the error. He also showed that the position of the model on which the localization is identified by the subject is also of importance. None of these studies has been primarily concerned 
with the mechanisms which enable higher level responses to be made in a way which is dependent on the locus of the tactile stimulus. Many of them have presupposed a fixed " sensory map" of a type which is incompatible with modern views of cortical physiology.

\section{Methods}

The method used here for the examination of tactile localization on the fingers is that of Henri (Head, 1920), in which the subject indicates on a three-dimensional model the position corresponding to the site of stimulation. As in Head's work the model used was the corresponding hand of one of the examiners. The subject was stimulated by a second examiner who used a wooden stylus with a $1 \mathrm{~mm}$. rounded end. The intensity of the stimulus was not precisely controlled but the stimulus may fairly be described as a light touch of about $\frac{1}{2}$-second duration. Stimuli which were not perceived at all were always repeated but not stimuli whose mere location was inadequately perceived. Most testing was done with the patient in bed. The stimulated hand lay comfortably on a board in the prone position with the fingers slightly spread. During stimulation the subject's hand and the experimenter's arm were shielded from the subject's view, but the model hand was continuously before the subject who was required to indicate the site of stimulation by pointing to the model with a pencil held in the free hand. The subject's response was recorded diagrammatically by one of the examiners.

During each test session the four fingers (but not the thumb) of both hands were stimulated four times. These four stimuli on each finger were placed two on either side of the finger, and the two stimuli on each side of the finger were placed one in the middle of the distal phalanx and one in the middle of the second phalanx. Each position was stimulated-once ; a total of 32 stimuli for every test session. Differential fatigue and practice effects on the two hands were obviated by alternating the stimulation of the two hands in groups of four stimuli. The order of stimulation of the two hands is shown by the series ABABBABA where each letter represents four stimuli to one hand, and a change of letter a change in the hand stimulated. In each hand, and on each occasion of testing, the order in which the sites were stimulated was random. As a further precaution the hand first stimulated on each occasion of testing was alternate to the hand first stimulated on the immediately previous test session. The thumb was not stimulated, because during the pilot stage of the investigation it was found that stimuli on the thumb were always correctly referred even when considerable difficulty was experienced in localizing stimuli on the fingers. Subjects were instructed that the stimuli would always occur on the sides of the fingers and either in the middle of the second or third phalanx and they were required to make their responses in accordance with these standards.

In estimating error in tactile localization two principal methods may be used. Either the direction and distance of the error may be recorded or else responses may be scored according to arbitrary standards of accuracy. Since it is not justifiable to regard the hand as an equipotential sensory surface, and since there are obvious difficulties attached to measuring extent of error when, for example, a stimulus is referred to the wrong finger, the second alternative has been adopted. This procedure is further justified by the fact that pilot studies suggested that errors were usually on a conceptual basis, e.g. the subject might refer the stimulus to the wrong finger but to the correct position on the finger.

The errors considered here are of three types : those involving a response referring the stimulus to the wrong finger, those referring the stimulus to the wrong side of the finger, and those referring the stimulus both to the wrong finger and to the wrong side of the finger. Errors involving a response referring the stimulus to the wrong phalanx are not considered here since it became obvious at an early stage that there was a strong tendency to refer the stimulus towards the nearest joint and this effect is already well known.

Twenty-two patients undergoing prefrontal leucotomy were examined before and after the operation.

AGE, SEX, AND DIAGNOSIS OF THE 22 SUBJECTS

\begin{tabular}{|c|c|c|c|}
\hline Subject & $\begin{array}{c}\text { Age at } \\
\text { Opera- } \\
\text { tion }\end{array}$ & Sex & Diagnosis \\
\hline $\begin{array}{l}19246 \\
30282 \\
18143 \\
11564 \\
24317 \\
28174 \\
28286 \\
12233 \\
11773 \\
19179 \\
15661 \\
8776 \\
14183 \\
18198 \\
18957 \\
8663 \\
23977 \\
14765\end{array}$ & $\begin{array}{l}21 \\
38 \\
41 \\
42 \\
44 \\
45 \\
47 \\
48 \\
48 \\
50 \\
50 \\
50 \\
52 \\
53 \\
53 \\
54 \\
55 \\
56\end{array}$ & $\begin{array}{l}\mathbf{F} \\
\mathbf{F} \\
\mathbf{M} \\
\mathbf{M} \\
\mathbf{M} \\
\mathbf{F} \\
\mathbf{F} \\
\mathbf{M} \\
\mathbf{M} \\
\mathbf{F} \\
\mathbf{F} \\
\mathbf{F} \\
\mathbf{M} \\
\mathbf{F} \\
\mathbf{F} \\
\mathbf{M} \\
\mathbf{M}\end{array}$ & $\begin{array}{l}\text { Facial tics ; depression } \\
\text { Depersonalization syndrome } \\
\text { Torsion dystonia ; depression } \\
\text { Anxiety state with chronic depression } \\
\text { Tinnitus, depression, following meningitis } \\
\text { Involutional depression } \\
\text { Chronic anxiety state } \\
\text { Schizophrenia } \\
\text { Chronic anxiety state } \\
\text { Chronic tuberculosis } \\
\text { Disseminated sclerosis ; hypochondriasis } \\
\text { Obsessional neurosis } \\
\text { Involutional depression } \\
\text { Involutional depression } \\
\text { Post-herpetic neuralgia ; depression } \\
\text { Hypochondriasis } \\
\text { Post-herpetic neuralgia } \\
\text { Hypochondriasis; depression ; ? organic }\end{array}$ \\
\hline $\begin{array}{r}25598 \\
9997 \\
13043 \\
14481\end{array}$ & $\begin{array}{l}56 \\
63 \\
63 \\
64\end{array}$ & $\begin{array}{l}\mathbf{M} \\
\mathbf{M} \\
\mathbf{F}\end{array}$ & $\begin{array}{l}\text { Post-herpetic neuralgia } \\
\text { Involutional depression } \\
\text { Post-herpetic neuralgia } \\
\text { Hypochondriasis }\end{array}$ \\
\hline
\end{tabular}


It was not possible to record enough errors from most subjects to establish individual pre-operative patterns and the results reported are those obtained for the group as a whole. In order to compare the results obtained before and after leucotomy, and to allow for differences in the number of test sessions of individual subjects, the results have been presented as error rates or errors per 100 stimuli. The percentage error at each stimulus site was calculated for each subject and thence a mean percentage error for the group was obtained. In the presence of individual differences in the distribution of errors such a method would not exclude undue weighting of the general pattern by patients who made frequent errors and might also produce artifactual changes in post-operative error distribution resulting from unequal impairment of subjects with different error distributions. A more accurate mean pattern would be obtained by averaging the pattern obtained by expressing individual error frequencies at the different stimulus sites as percentages of the total number of errors made by the subject. Such an analysis has been made and it is clear that no material distortion in pattern can be attributed to the method of analysis first described.

In order to avoid repetition and to allow comparison between pre- and post-operative performance the former method of analysis is alone presented here. Where necessary raw figures are also reported to allow of the assessment of the significance of the percentage figures. All statistical tests of significance were applied to the raw data.$$
\text { cance were applied to the raw data. }
$$

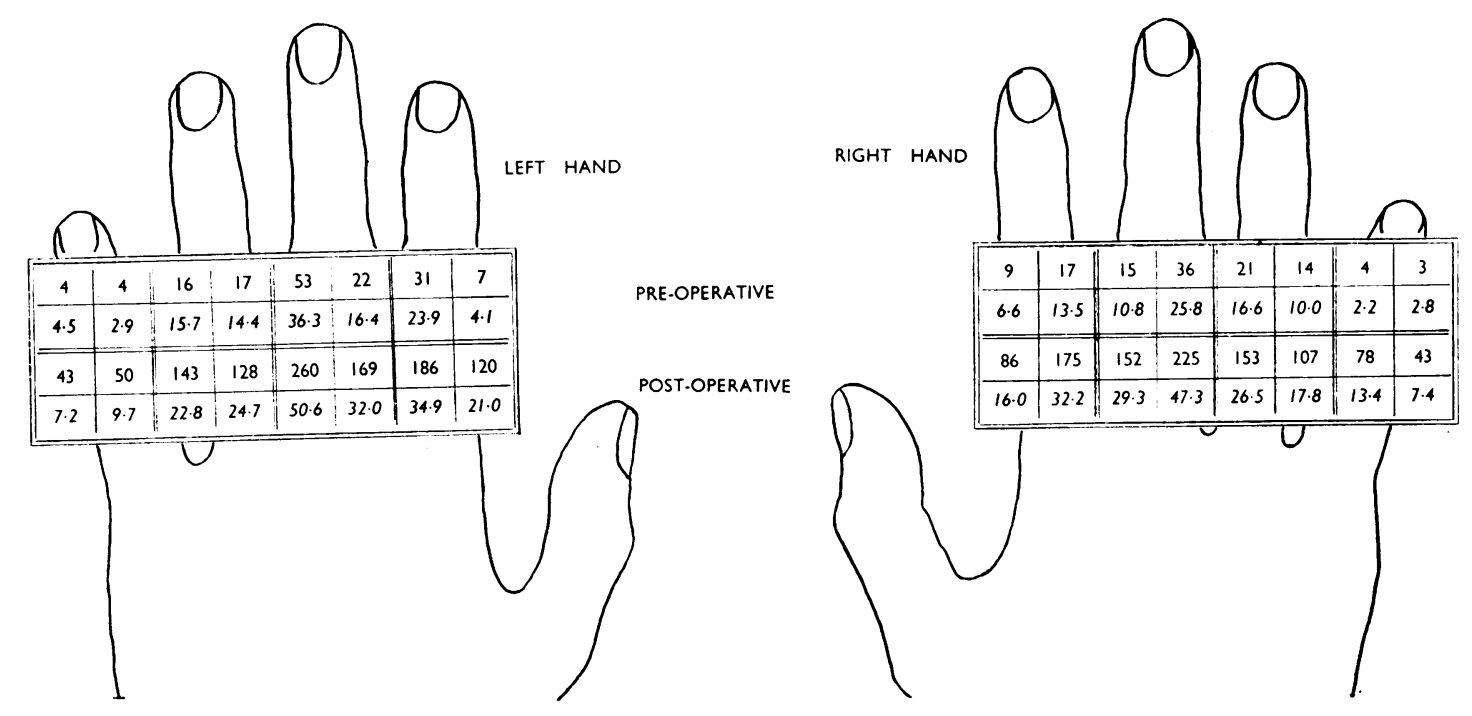

FIG. 1. - This figure shows the number of errors which occurred at each stimulus site in 22 subjects. The figures in italics show the mean error rates for these subjects expressed as a percentage of the number of stimuli at each site.

\section{Errors of tactile localization were made pre-} operatively by all our subjects. Post-operatively there was an increase in the frequency of errors. These errors are described first according to the site of occurrence and secondly according to the type of error.

Incidence of Errors.-Pre-operatively a total of 2,064 stimuli were applied to our 22 subjects and of these $273(13 \%)$ were incorrectly localized. This high incidence of errors was largely due to lack of practice on a novel test. After leucotomy 2,118 $(21 \%)$ of 10,096 stimuli were incorrectly localized, an increase in the frequency of errors which is clearly significant $(p<0.001)$. Only very occasionally was the patient too confused to cooperate on the first post-operative day. If the subject was able to attempt the task then some stimuli were correctly located. Performance was most seriously impaired immediately post-operatively and improved as convalescence progressed. The error frequency for the first four weeks was $26 \cdot 1 \%, 22.5 \%, 22.0 \%$, and $16.4 \%$ respectively.

The frequency with which errors occurred was not the same at each site of stimulation nor for each hand. The distribution of errors over the two hands is shown in Fig. 1. In order that the preand post-operative patterns can be compared, and to exclude excessive weighting of the pattern by any one subject, the error at each site is also expressed as the mean percentage error for all 22 subjects. 
It is clear that the distribution of errors is not a random one and that mistakes in localizing tactile stimuli are much more frequent at some sites than others. Further it is apparent that these differences between the various sites are very similar on the two hands and that the patterns post-operatively closely resemble those found before leucotomy. Thus on each hand before and after operation the fifth finger is the one at which fewest errors are made. Similarly on both hands both before and after the operation most errors occur following stimulation of the ulnar side of digit 3 where the error frequency is between six and $\mathbf{1 0}$ times that at the ulnar side of digit 5. A $\chi^{2}$ test of significance can be applied to check that the observed distribution of errors over the eight sites on the hand is not likely to have arisen by chance. Pre-operatively, when the errors at corresponding sites on the two hands are summed, the value for $\chi^{2}$ is found to be 152.3. A similar result is obtained post-operatively when the increase in the number of observations gives an even higher value for $\chi^{2}(451.8)$ and so an even more significant result.

It is clear therefore that our subjects, most of whom are free from neurological lesions, are liable under the conditions of this investigation to make gross mistakes when localizing tactile stimuli on the hand, i.e. indicate the wrong finger or the wrong side of the finger. This generalization from the summed results is justified by the observation that each of our 22 subjects made at least one error. pre-operatively.

The frequency with which errors occur is determined to a considerable extent by the site of stimulation. As, however, the distribution of the errors is related to the type of error made, this effect is reported before making a detailed analysis of the distribution.

Type of Errors. - Table I shows the distribution of errors and the sites to which errors made at each of the 16 stimulus points were referred. As an example, 53 errors or $36.3 \%$ of the stimuli applied pre-operatively to the ulnar side of the third finger on the left hand were incorrectly localized. These errors were referred to the other seven sites as shown in row $3 \mathrm{U}$ in the top left hand matrix.

It is apparent that both before and after operation errors are not referred to other sites in a random fashion but that when a stimulus is incorrectly localized the site of reference depends on the site of stimulation. This departure from a purely random reference of errors is not due to chance, as is shown by calculating the value for $\chi^{2}$ for our observed distribution. This has been done by summing the pre- and post-operative results and the results for both hands and calculating $\chi^{2}$ for the distribution of error referrals in the case of each stimulus site (Table II). The eight values for $\chi^{2}$ thus obtained are all significant at the 0.001 level of confidence. The pre-operative figures are not examined separately because pre-operatively the number of errors at some sites is too few to permit the application of the $\chi^{2}$ test.

This relationship might seem to justify the assumption that the error is a quantitative one and that the incorrectly perceived stimuli are most frequently referred to the next nearest site. In this case the error tendency would be suitably represented by the extent of skin surface intervening between the site of stimulation and the site of reference. On this hypothesis there would be an inverse relationship between the extent of the errors and their frequency. Closer inspection of the data presented in Table I shows, however, that in the case of 10 of the 16 sites of stimulation pre-operatively and 11 of the 16 sites post-operatively more errors were referred to a position at two removes from the site of stimulation than to the position immediately adjacent to the stimulus site. That is to say, errors are more frequently referred to the corresponding position on an adjacent finger than to the wrong side of the stimulated finger. Similarly, when errors are referred to an adjacent finger most of these errors are referred by the subject to the side of the finger corresponding to the stimulated side of the stimulated finger. This occurs irrespective of whether that side is nearest to or more remote from the stimulated finger than the alternative side. Thus in both hands pre- and post-operatively three times as many of the stimuli applied to the ulnar side of the third finger are referred to the ulnar side of finger 4 as are referred to the radial side of this finger, although this latter side is nearer to the site stimulated. Similarly, many more of the stimuli applied to the radial side of the fourth finger are referred to the radial side of the third finger than are referred to its ulnar side.

The fact that one aspect of the stimulus situation is correctly perceived even when the total interpretation is wrong suggests that localization is taking place on a "conceptual" basis and that localizing responses are made to more than one spatial attribute or dimension characterizing the site of the stimulus. These different aspects of the stimulus may be perceived with different degrees of accuracy. Two such dimensions appear to be present in the particular performance under investigation. These are (1) the finger stimulated, and (2) the side of the finger stimulated. 
TABLE I

SITES OF STIMULATION AND DISTRIBUTION OF ERRORS* PRE-OPERATIVELY AND POST-OPERATIVELY FOR LEFT AND RIGHT HANDS BY 22 SUBJECTS

Pre-operative

Left Hand

SITES OF REFERENCE OF ERRORS

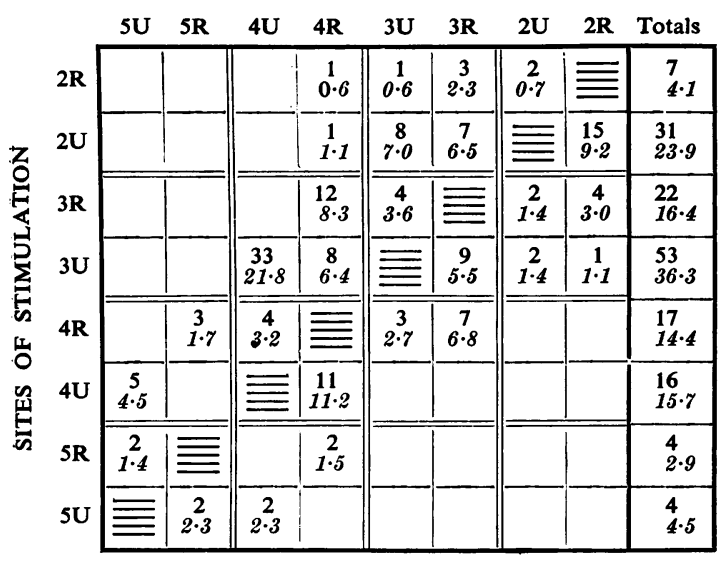

Right Hand

SITES OF REFERENCE OF ERRORS

\begin{tabular}{|c|c|c|c|c|c|c|c|c|}
\hline Totals & $2 R$ & $2 \mathbf{U}$ & 3R & $3 \mathrm{U}$ & $4 R$ & $\mathbf{4 U}$ & $5 R$ & $5 \mathrm{U}$ \\
\hline$\underset{6 \cdot 6}{9}$ & $\equiv$ & $\begin{array}{c}3 \\
2 \cdot 7\end{array}$ & $\begin{array}{l}6 \\
4 \cdot 0\end{array}$ & & & & & \\
\hline $\begin{array}{l}17 \\
13.5\end{array}$ & $\begin{array}{l}12 \\
9 \cdot 6\end{array}$ & $\equiv$ & $\frac{1}{1 \cdot 1}$ & $\begin{array}{c}3 \\
2 \cdot 0\end{array}$ & & & & $\begin{array}{c}1 \\
0.8\end{array}$ \\
\hline $\begin{array}{l}15 \\
10 \cdot 8\end{array}$ & $\begin{array}{l}4 \\
3 \cdot 4\end{array}$ & & $\equiv$ & $\begin{array}{c}4 \\
1 \cdot 2\end{array}$ & $\begin{array}{c}6 \\
5 \cdot 9\end{array}$ & $\begin{array}{c}1 \\
0 \cdot 3\end{array}$ & & \\
\hline $\begin{array}{l}36 \\
25 \cdot 8\end{array}$ & & $\frac{1}{1 \cdot 1}$ & $\begin{array}{c}8 \\
5 \cdot 2\end{array}$ & $\equiv$ & $\begin{array}{c}2 \\
0.8\end{array}$ & $\begin{array}{c}24 \\
17.9\end{array}$ & & $\begin{array}{c}1 \\
0.8\end{array}$ \\
\hline $\begin{array}{l}21 \\
16 \cdot 6\end{array}$ & & $\begin{array}{c}1 \\
0 \cdot 4\end{array}$ & $\begin{array}{c}9 \\
8 \cdot 3\end{array}$ & $\begin{array}{c}2 \\
2 \cdot 3\end{array}$ & $\equiv$ & $\begin{array}{c}6 \\
3 \cdot 7\end{array}$ & $\begin{array}{c}3 \\
1.9\end{array}$ & \\
\hline $\begin{array}{l}14 \\
10 \cdot 0\end{array}$ & & & $\begin{array}{c}1 \\
0.8\end{array}$ & $\begin{array}{c}3 \\
3 \cdot 0\end{array}$ & $\begin{array}{c}4 \\
2 \cdot 8\end{array}$ & $\equiv$ & $\begin{array}{c}1 \\
0.8 \\
\end{array}$ & $\begin{array}{c}5 \\
2 \cdot 7\end{array}$ \\
\hline $\begin{array}{l}4 \\
2 \cdot 2\end{array}$ & & & & & & & $\bar{\equiv}$ & $\stackrel{4}{2 \cdot 2}$ \\
\hline $\begin{array}{l}3 \\
2 \cdot 8\end{array}$ & & & & & & & $\begin{array}{c}3 \\
2 \cdot 8\end{array}$ & $\equiv$ \\
\hline
\end{tabular}

Post-operative

\begin{tabular}{|c|c|c|c|c|c|c|c|c|c|}
\hline & $5 U$ & $5 R$ & $4 U$ & $4 R$ & $3 U$ & 3R & $\mathbf{2 U}$ & $2 R$ & Totals \\
\hline \multirow{3}{*}{ 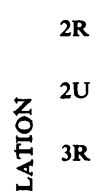 } & $\begin{array}{c}3 \\
0 \cdot 5\end{array}$ & $\begin{array}{c}12 \\
1 \cdot 7\end{array}$ & & $\begin{array}{r}16 \\
2 \cdot 7\end{array}$ & $\begin{array}{r}3 \\
0 \cdot 4\end{array}$ & $\begin{array}{c}38 \\
6 \cdot 4\end{array}$ & $\begin{array}{c}48 \\
9 \cdot 3\end{array}$ & $\equiv$ & ${ }_{21 \cdot 0}^{120}$ \\
\hline & $\begin{array}{c}1 \\
0 \cdot 1\end{array}$ & $\begin{array}{l}11 \\
1.5\end{array}$ & $\begin{array}{c}18 \\
3 \cdot 3\end{array}$ & $\begin{array}{r}16 \\
4 \cdot 0\end{array}$ & $\begin{array}{l}49 \\
8.7\end{array}$ & $\begin{array}{r}23 \\
3 \cdot 3 \\
\end{array}$ & $\equiv$ & $\begin{array}{r}68 \\
14 \cdot 1\end{array}$ & $\stackrel{186}{34.9}$ \\
\hline & $\begin{array}{r}1 \\
0 \cdot 1\end{array}$ & $\begin{array}{l}10 \\
1.4\end{array}$ & $\begin{array}{r}9 \\
1 \cdot 4\end{array}$ & $\mid \begin{array}{r}71 \\
15 \cdot 2\end{array}$ & $\begin{array}{r}31 \\
5 \cdot 2\end{array}$ & $\equiv$ & $\begin{array}{r}14 \\
2 \cdot 7\end{array}$ & $\begin{array}{r}33 \\
6.0\end{array}$ & $\begin{array}{c}169 \\
32 \cdot \cap\end{array}$ \\
\hline $3 \mathbf{U}$ & $\begin{array}{r}8 \\
0.9\end{array}$ & $\begin{array}{r}8 \\
0.9\end{array}$ & $\begin{array}{c}118 \\
27 \cdot 6\end{array}$ & $\begin{array}{c}42 \\
7 \cdot 8\end{array}$ & $\equiv$ & $\begin{array}{r}71 \\
11 \cdot 4\end{array}$ & $\begin{array}{l}12 \\
1.9\end{array}$ & $\begin{array}{r}1 \\
0.2\end{array}$ & $\begin{array}{c}260 \\
50 \cdot 6\end{array}$ \\
\hline $4 R$ & $\begin{array}{r}4 \\
0.7\end{array}$ & $\begin{array}{r}25 \\
3.9\end{array}$ & $\begin{array}{c}20 \\
4 \cdot 9\end{array}$ & $\equiv$ & $\begin{array}{c}14 \\
3 \cdot 1\end{array}$ & $\begin{array}{r}54 \\
9 \cdot 8\end{array}$ & $\begin{array}{r}3 \\
0 \cdot 3\end{array}$ & $\begin{array}{r}8 \\
2 \cdot 0\end{array}$ & $\begin{array}{c}128 \\
24 \cdot 7\end{array}$ \\
\hline $4 U$ & $\begin{array}{r}14 \\
2 \cdot 6\end{array}$ & $\begin{array}{r}20 \\
2 \cdot 8\end{array}$ & $\equiv$ & $\begin{array}{r}75 \\
11 \cdot 0\end{array}$ & $\begin{array}{c}26 \\
4 \cdot 7\end{array}$ & $\begin{array}{r}6 \\
0.9\end{array}$ & & $\begin{array}{r}2 \\
0.8\end{array}$ & $\begin{array}{c}143 \\
22 \cdot 8\end{array}$ \\
\hline $5 R$ & $\begin{array}{c}12 \\
2 \cdot 4\end{array}$ & $\bar{\equiv}$ & $\begin{array}{r}6 \\
1 \cdot 1\end{array}$ & $\begin{array}{l}27 \\
5 \cdot 0\end{array}$ & & $\begin{array}{r}2 \\
0.5\end{array}$ & & $\begin{array}{r}3 \\
0.7\end{array}$ & $\stackrel{50}{9 \cdot 7}$ \\
\hline & 竎 & $\begin{array}{r}25 \\
3 \cdot 6\end{array}$ & $\begin{array}{l}16 \\
3 \cdot 4\end{array}$ & $\begin{array}{r}2 \\
0.2\end{array}$ & & & & & $\stackrel{43}{7 \cdot 2}$ \\
\hline
\end{tabular}

\begin{tabular}{|c|c|c|c|c|c|c|c|c|c|}
\hline Totals & $2 \mathbf{R}$ & $2 U$ & 3R & $3 \mathbf{U}$ & 4R & $\mathbf{4 U}$ & $5 R$ & $5 U$ & \\
\hline $\begin{array}{c}86 \\
16 \cdot 0\end{array}$ & 立 & $\begin{array}{l}25 \\
4 \cdot 4\end{array}$ & $\begin{array}{l}29 \\
6 \cdot 5\end{array}$ & $\begin{array}{c}4 \\
0.6\end{array}$ & $\begin{array}{l}20 \\
3 \cdot 4\end{array}$ & $\begin{array}{c}5 \\
0 \cdot 7\end{array}$ & $\begin{array}{c}1 \\
0 \cdot 2\end{array}$ & $\stackrel{2}{0 \cdot 3}$ & $2 R$ \\
\hline $\begin{array}{l}175 \\
32 \cdot 2\end{array}$ & $\begin{array}{l}42 \\
9 \cdot 2\end{array}$ & $\equiv$ & $\begin{array}{l}32 \\
5 \cdot 3\end{array}$ & $\begin{array}{c}51 \\
10 \cdot 1\end{array}$ & $\begin{array}{l}20 \\
2 \cdot 8\end{array}$ & $\begin{array}{l}17 \\
3 \cdot 2\end{array}$ & $\begin{array}{l}11 \\
1 \cdot 4\end{array}$ & $\stackrel{2}{0 \cdot 3}$ & $2 U$ \\
\hline $\begin{array}{l}152 \\
29 \cdot 3\end{array}$ & $\begin{array}{l}40 \\
6.9\end{array}$ & $\begin{array}{l}10 \\
1.5\end{array}$ & $\bar{\equiv}$ & $\begin{array}{l}22 \\
3 \cdot 9\end{array}$ & $\begin{array}{r}66 \\
15 \cdot 1\end{array}$ & $\begin{array}{c}8 \\
1 \cdot 2\end{array}$ & $\begin{array}{c}6 \\
0.7\end{array}$ & & $3 R$ \\
\hline $\begin{array}{l}225 \\
47 \cdot 3\end{array}$ & $\begin{array}{c}2 \\
0 \cdot 2\end{array}$ & $\begin{array}{l}12 \\
2 \cdot 7\end{array}$ & $\begin{array}{l}47 \\
8 \cdot 3\end{array}$ & $\equiv$ & $\begin{array}{l}36 \\
6.9\end{array}$ & $\begin{array}{l}123 \\
28.5\end{array}$ & $\begin{array}{c}3 \\
0 \cdot 4\end{array}$ & $\begin{array}{c}2 \\
0 \cdot 3\end{array}$ & $3 U$ \\
\hline $\begin{array}{l}153 \\
26 \cdot 5\end{array}$ & $\begin{array}{c}5 \\
0 \cdot 7\end{array}$ & $\begin{array}{c}2 \\
0 \cdot 3\end{array}$ & $\begin{array}{c}70 \\
10 \cdot 4\end{array}$ & $\begin{array}{l}11 \\
1.7\end{array}$ & $\equiv$ & $\begin{array}{l}32 \\
7 \cdot 8\end{array}$ & $\begin{array}{l}31 \\
5.0\end{array}$ & $\begin{array}{c}2 \\
0.3\end{array}$ & $4 R$ \\
\hline $\begin{array}{l}107 \\
17 \cdot 8\end{array}$ & $\begin{array}{c}2 \\
0 \cdot 3\end{array}$ & & $\begin{array}{c}6 \\
0 \cdot 8\end{array}$ & $\begin{array}{c}30 \\
5 \cdot 2\end{array}$ & $\begin{array}{l}33 \\
5 \cdot 1\end{array}$ & $\bar{\equiv}$ & $\begin{array}{l}14 \\
2 \cdot 5\end{array}$ & $\begin{array}{l}22 \\
3.9\end{array}$ & $4 U$ \\
\hline $\begin{array}{c}78 \\
13 \cdot 4\end{array}$ & $\begin{array}{c}2 \\
0 \cdot 2\end{array}$ & & $\begin{array}{l}10 \\
1.4\end{array}$ & & $\begin{array}{l}41 \\
6 \cdot 3\end{array}$ & $\begin{array}{ll}11 \\
1 \cdot 6\end{array}$ & $\bar{\equiv}$ & $\begin{array}{l}14 \\
3.9\end{array}$ & $5 R$ \\
\hline $\begin{array}{l}43 \\
7 \cdot 4\end{array}$ & & $\begin{array}{c}1 \\
0 \cdot 2\end{array}$ & $\begin{array}{c}1 \\
0 \cdot 2\end{array}$ & $\begin{array}{c}4 \\
0 \cdot 5\end{array}$ & $\begin{array}{c}4 \\
0 \cdot 5\end{array}$ & $\begin{array}{l}12 \\
1.9\end{array}$ & $\begin{array}{l}21 \\
4 \cdot 2\end{array}$ & $\equiv$ & $5 U$ \\
\hline
\end{tabular}

* The figures in each row show to which positions the errors at a particular site of stimulation were referred. The totals columns give the total number of errors which occurred at each stimulus site. The actual errors are in roman type and the errors expressed as a percentage of the number of stimuli at each site are in italics. The hatched squares are those sites to which stimuli were correctly referred and at which therefore no error occurred.

Within these terms of reference two main types of error can occur : finger errors and side errors. There is no a priori reason why the occurrence of these two types of error should depend on the same factors and it was thought worth while to analyse them separately. For the purpose of this analysis finger errors are those errors in which the finger is incorrectly indicated regardless of the correctness or otherwise of the localization of the side of the finger stimulated. Similarly, side errors occur when the stimulus is referred to the wrong side of the finger whether the finger is correctly localized or not. The mutually inclusive case of "mislocalizaton" of both the finger and the side in the same response is not considered separately.

In Fig. 2 the distributions of finger errors and side errors are presented graphically in the form of histograms. It is at once apparent that patterns of distribution for the two types of error are markedly different. Both types of error are on the average 
TABLE II

DISTRIBUTION OF ALL ERRORS* BEFORE AND AFTER OPERATION

\begin{tabular}{|c|c|c|c|c|c|c|c|c|c|c|c|}
\hline \multirow[t]{2}{*}{$\begin{array}{l}\text { Sites of } \\
\text { Stimulation }\end{array}$} & \multicolumn{8}{|c|}{$\begin{array}{l}\text { Sites to which Stimuli are } \\
\text { Erroneously Referred }\end{array}$} & \multirow{2}{*}{$x^{2}$} & \multirow{2}{*}{$\begin{array}{l}\text { Degrees of } \\
\text { Freedom }\end{array}$} & \multirow{2}{*}{$\stackrel{\text { P }}{\text { (Level of Significance) }}$} \\
\hline & $2 \mathrm{R}$ & $2 \mathrm{U}$ & $3 \mathbf{R}$ & $3 \mathrm{U}$ & $4 R$ & $4 \mathrm{U}$ & $5 \mathrm{R}$ & $5 \mathrm{U}$ & & & \\
\hline $2 \mathrm{R}$ & $\equiv$ & 78 & 76 & 8 & 37 & 5 & 13 & 5 & $204 \cdot 1$ & 6 & $<0.001$ \\
\hline $2 U$ & 137 & 立 & 62 & 109 & 40 & 35 & 22 & 4 & $238 \cdot 4$ & 6 & $<0.001$ \\
\hline $3 R$ & 81 & 26 & $\equiv$ & 61 & 155 & 18 & 16 & 1 & $337 \cdot 6$ & 6 & $<0.001$ \\
\hline $3 \mathrm{U}$ & 4 & 27 & 135 & 三 & 88 & 298 & 11 & 11 & $837 \cdot 8$ & 6 & $<0.001$ \\
\hline $4 R$ & 13 & 6 & 140 & 30 & $\equiv$ & 62 & 62 & 6 & $410 \cdot 8$ & 6 & $<0.001$ \\
\hline $4 U$ & 4 & 0 & 13 & 59 & 123 & 无 & 35 & 46 & $273 \cdot 3$ & 6 & $<0.001$ \\
\hline $5 R$ & 5 & 0 & 12 & 0 & 70 & 17 & $\equiv$ & 32 & 192.8 & 6 & $<0.001$ \\
\hline $5 \mathrm{U}$ & 0 & 1 & 1 & 4 & 6 & 30 & 51 & $\equiv$ & $174 \cdot 5$ & 6 & $<0.001$ \\
\hline
\end{tabular}

* The errors made on each hand are summed and presented as in Table I.

more frequent following stimulation of the ulnar side of a finger but in the case of side errors this ulnar predominance is much more marked. Summing the pre- and post-operative results (raw data) for both hands, ulnar side errors are in fact 2.05 times as frequent as radial side errors, whereas in the case of finger errors the proportion is $1 \cdot 1$ to 1 . Again the incidence of the two types of error is different for the individual fingers, side errors occurring most frequently on the radial side of the hand whereas finger errors predominate on the two central fingers. A $\chi^{2}$ test (Table III) shows that the distributions over the eight sites of finger errors and of side errors are different to a significant degree. In addition to the difference in frequency between ulnar side errors and ulnar finger errors there is also a marked difference between the distributions over the four fingers of the two types of ulnar error. Fig. 2 shows clearly that in the case of ulnar side errors there is a gradient of increasing weakness from the ulnar to the radial side of the hand. Although ulnar finger errors are also more frequent on the radial side of the hand, there is not the same gradient of weakness and the errors are distributed more with respect to the inside (centre) and outside (periphery) of the hand. This tendency for finger errors following stimulation of the ulnar side of a finger (ulnar errors) to increase towards the centre of the hand also characterizes radial finger errors and indeed is characteristic of finger errors as a group.

The remaining errors, radial side errors, are not distributed in a way which is obviously similar to the distribution of ulnar side errors. Like the finger errors they tend to be more frequent on the central fingers and, with the exception of the left hand post-operatively, they are more frequent on the ulnar side of the hand.

The observation that the factors governing the occurrence of side errors and finger errors appear to be different and that the differences in the distributions reach a high level of significance justify the

TABLE III

DIFFERENCE IN DISTRIBUTION OF SIDE ERRORS AND FINGER ERRORS*

\begin{tabular}{|c|c|c|c|c|c|c|c|c|c|c|}
\hline & & \multicolumn{8}{|c|}{ Site of Errors } & \multirow{2}{*}{ Totals } \\
\hline & & $2 \mathbf{R}$ & $2 U$ & $3 \mathbf{R}$ & $3 U$ & $4 \mathrm{R}$ & $4 U$ & $5 \mathrm{R}$ & $5 U$ & \\
\hline Side errors & $\ldots$ & 96 & 257 & 106 & 237 & 104 & 175 & 49 & 58 & 1,082 \\
\hline Finger errors & .. & 154 & 262 & 295 & 440 & 257 & 157 & 104 & 42 & 1,711 \\
\hline Totals & $\ldots$ & 250 & 519 & 401 & 677 & 361 & 332 & 153 & 100 & 2,793 \\
\hline
\end{tabular}

* These figures are obtained by summing the pre-operative and post-operative results for both hands for the 22 subjects. The difference between the distributions gives a value for $\chi^{2}$ of $482 \cdot 3$, which, with 7 degrees of freedom, is highly significant $(P<0 \cdot 001)$. 


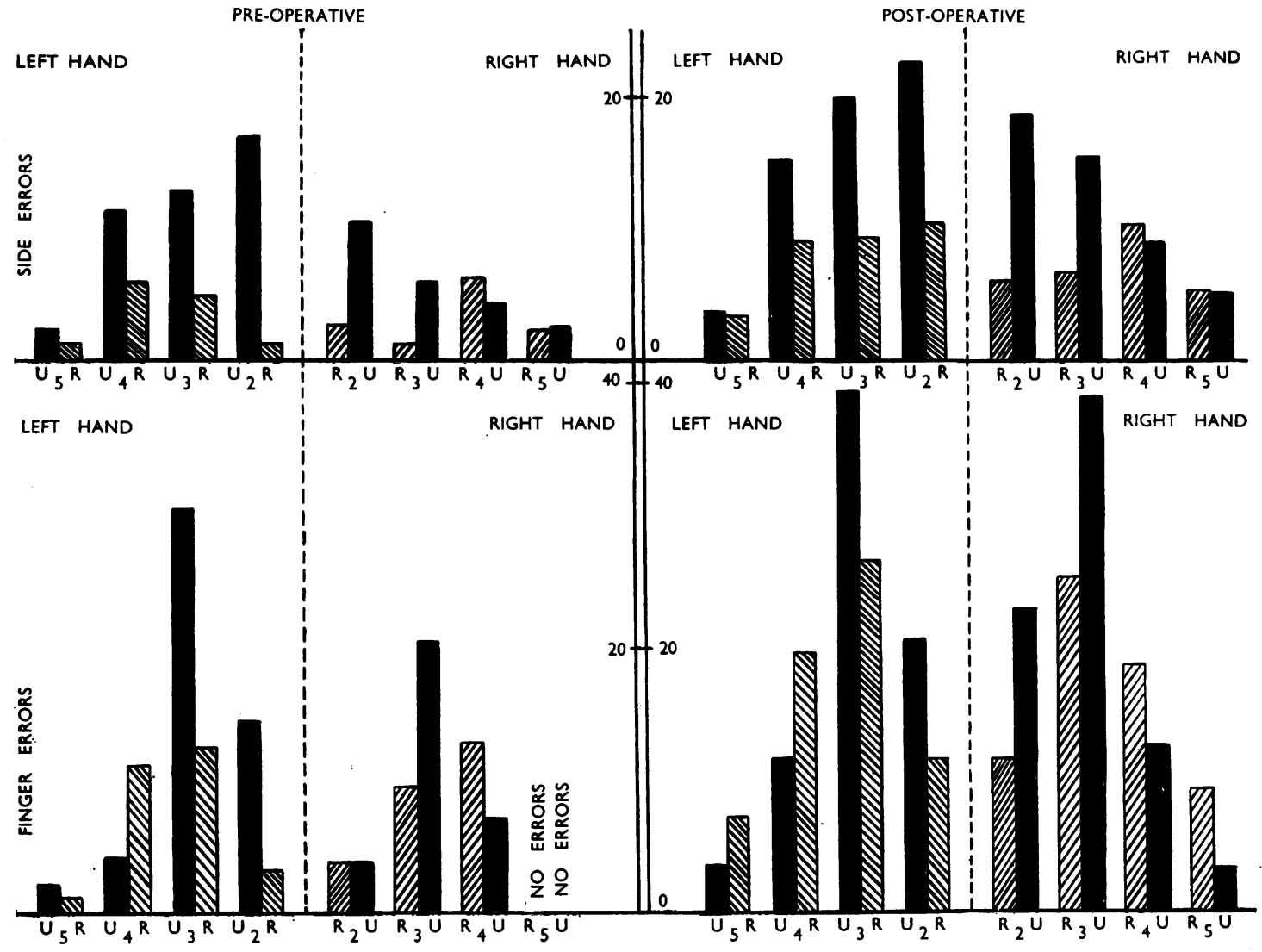

Fig. 2.-The incidence of finger errors and of side errors is given in separate histograms. The errors are shown for each side of each finger, both pre-operatively and post-operatively. Radial errors are hatched, those following ulnar stimulation are in black.

conclusion that the type of error which occurs most frequently (finger error or side error) is a function of the site of stimulation.

Direction of Errors.-The sites to which stimuli on the fingers are erroneously referred may also be considered with respect to the direction of mislocalization. This is not an independent variable since the opportunities for displacement in a given direction vary with the site of stimulation. Thus, in the case of side errors, stimuli on the ulnar side of a finger can only be referred to the radial side of a finger, and, in the case of finger errors, stimuli of digits 5 and 2 can only be referred in radial and ulnar directions respectively. Stimuli on digits 3 and 4 may be referred to fingers in either direction, but it is clear that there is a greater probability of a finger error following stimulation of digit 3 being referred in an ulnar direction than in a radial direction, and conversely for digit 4 .
It has been pointed out above that in the case of side errors $67 \cdot 2 \%$ of these errors follow stimulation of the ulnar side of a finger. This is equivalent to saying that $67 \cdot 2 \%$ of side errors are referred in a radial direction since, in the case of side errors, direction of referral and the side of the finger on which the error occurs are interdependent.

In the case of finger errors $81.4 \%$ of such errors occurring on digit 3 and $36.0 \%$ of those occurring on digit 4 are referred in an ulnar direction. That is to say, in the case of both of the fingers in which there is some freedom in the direction in which finger errors may be referred there is a tendency for errors to be referred towards the middle two fingers of the hand. Analysis of Table I shows that there is an overall tendency for finger errors to be referred in an ulnar direction $(68 \%)$ rather than in a radial direction. This cannot be accounted for by the excess of errors on digit 3.

A more striking result is the dependence which is 
TABLE IV

CONTINGENCY BETWEEN DIRECTION OF FINGER ERRORS AND SIDE OF FINGER STIMULATED FOR FINGERS 3 AND 4*

\begin{tabular}{|c|c|c|c|c|c|c|c|c|}
\hline \multicolumn{5}{|c|}{ Finger 3} & \multicolumn{4}{|c|}{ Finger 4} \\
\hline & & $\underset{\text { Stimulation }}{\text { Ulnar }}$ & $\begin{array}{c}\text { Radial } \\
\text { Stimulation }\end{array}$ & Totals & & $\underset{\text { Stimulation }}{\text { Ulnar }}$ & $\begin{array}{l}\text { Radial } \\
\text { Stimulation }\end{array}$ & Tota!s \\
\hline $\begin{array}{l}\text { Finger errors } \\
\text { ulnarly }\end{array}$ & referred & 408 & 190 & 598 & $\begin{array}{l}\text { Finger errors referred } \\
\text { ulnarly }\end{array}$ & 81 & 70 & 151 \\
\hline $\begin{array}{l}\text { Finger errors } \\
\text { radially }\end{array}$ & referred & 31 & 107 & 138 & $\begin{array}{l}\text { Finger errors referred } \\
\text { radially }\end{array}$ & 72 & 189 & 261 \\
\hline Totals & $\ldots$ & 439 & 297 & 736 & Totals & 153 & 259 & 412 \\
\hline
\end{tabular}

* These figures are obtained by summing the pre-operative and post-operative results for the 22 subjects. Finger $3: \chi^{2}=97 \cdot 6$, which, with 1 degrez of freedom, is significant $(\mathrm{p}<0.001)$. Finger $4: \chi^{2}=27 \cdot 8$, which, with 1 degree of freedom, is significant $(\mathrm{p}<0.001)$.

observed of the direction of referral of finger errors upon the side of the finger stimulated (Table JV). Errors following stimulation of the ulnar side of a finger are more frequently displaced in an ulnar direction while those following radial stimulation tend to be displaced radially. In the case of digit $3 \mathrm{a} \chi^{2}$ test shows the contingency of direction of reference of finger errors upon the side of the finger stimulated to be significant at the 0.001 level of confidence $\left(\%^{2}=97.6\right)$. In the case of digit 4 the test gives a result which is also significant at the 0.001 level $\left(\chi^{2}=27 \cdot 8\right)$. The test cannot be applied in the case of digits 2 and 5 since in both these cases finger errors can be referred in only one direction, ulnarly and radially respectively.

It has been reported above that side errors following stimulation of the ulnar side of the fingers were much more frequent on the radial side of the hand and that radial side errors were slightly more frequent on the ulnar side of the hand. This fact may be expressed in terms of the direction of displacement of errors : the direction of displacement of side errors is contingent on the side of the hand stimulated, side errors on the fingers on the radial side of the hand tending to be displaced radially and conversely for side errors on the ulnar side of the hand.

These two effects, the contingency of the direction of finger errors on the side of the finger stimulated and the contingency of direction of side errors on the side of the hand stimulated, may be due to a " contamination" between two conceptual systems involved in the performance of the task. These two conceptual systems would relate to perception of the side of the hand stimulated and to perception of the side of the finger stimulated. Such evidence has implications for a theory of tactile local sign and will be discussed below.

\section{Further Observations}

Presentation of our observations in a summary manner tends to obscure the details of the errors made by our subjects. Thus in the immediate post-operative period one or two seriously confused patients made bizarre types of response. On one occasion one subject remorselessly indicated each finger in turn regardless of the site of stimulation. For a short time post-operatively several patients made errors of a perseverative type, repeatedly indicating the same position although successive stimuli were at different sites. It was also apparent that subjects would occasionally confuse the two sides of the hand. Following stimulation of the second finger, for example, a subject would hesitate between the two sides of the hand but show no interest in the middle two fingers. It was also clear that mislocalization was not always related to a feeling of uncertainty. Thus for several sessions a subject would place the site of a particular stimulus incorrectly but with complete confidence and with no tendency to make a correct response.

Individual differences in error pattern were quite marked post-operatively, but as only six subjects made 10 or more errors each pre-operatively, it was not usually possible to establish that these individual differences existed before operation. In order to elucidate this point an alternative method of investigating tactile localization has been devised and the results will be reported in a subsequent communication.

In using the method of Henri we have assumed that the localization of stimuli to a three dimensional model is a task which is essentially similar to the localization of stimuli to the actual site of stimulation on the hand of the subject. Both of these tasks involve matching in the sense in which Head employed the term, and this, he claimed, did not involve verbalization. It seems likely that the difference between the two tasks is in the degree of difficulty rather than in the nature of the functions involved. Observation of a few of our patients showed that, even when the "groping error" is excluded, localization to the subject's own hand was a more accurate performance but errors of a 
"conceptual" type were still present. Thus different distributions of errors at the different sites were observed in the case of finger errors and side errors, as were some of the contaminatory effects discussed above. Differences between the results obtained using the two methods did occur but these differences were not such as might alter the theoretical position maintained in this paper with respect to errors made in localizing to a model. It is hoped to report in a later paper differences due to variations in technique and their implications for a theory of tactile localization.

\section{Effect of the Operation}

In the main analysis little distinction has been made between the results obtained pre-operatively and those obtained after leucotomy. This has been justified by the consistency of the results obtained and the close similarity of pre-operative and post-operative error patterns. Nevertheless, differences do exist. It has been reported above that the total percentage of errors increases following the operation. In addition to this there are some changes in the distribution of errors on the hands. In the case of the left hand (Table V) a $\chi^{2}$ test shows

TABLE V

DISTRIBUTION OF ERRORS ON THE LEFT HAND FOLLOWING LEUCOTOMY*

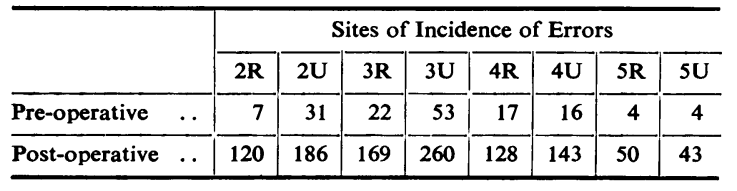

* The figures shown in this table are the total errors made on the left hand by the 22 subjects. $x^{2}=15 \cdot 3$, which, with 7 degrees of freedom, is significant $(\mathrm{p}<0.05)$.

that the post-operative distribution of errors on the eight sites is different from the distribution observed pre-operatively at the 0.05 level of significance $\left(\chi^{2}=15 \cdot 3\right)$. The same test applied in the case of the right hand gives an insignificant value for $\chi^{2}$. That is to say, there is no difference between the pre- and post-operative distributions of total errors on the right hand which is not easily attributable to chance. Inspection of the original data suggests that the change in the left hand is accounted for largely by a post-operative decrease in the number of side errors following stimulation of the ulnar side of a finger in the left hand. It is noteworthy that the effect of this decrease is to make the distribution or errors on the two hands more similar post-operatively than was the case pre-operatively. Thus, when errors are expressed as the percentage of the number of stimuli, post- operatively the rank order of the different sites with respect to error frequency is identical in the two hands, whereas pre-operatively there are six discrepancies in rank order, one site differing in the two hands to the extent of three positions of rank order.

Unfortunately, when the data under consideration are the results summed for all subjects, unequivocal changes in the distribution of errors following operation cannot be proved. This is precluded by the possibility that individual subjects with different error patterns may be unequally impaired by the operation and so produce an artifactual change in the mean pattern of errors.

It is not proposed to discuss individual differences in detail here, as this question will be reported upon elsewhere. However, it may be said that our results suggest that, in at least some of our subjects, the operation produces a change in the distribution of errors. Thus, in two of our subjects it can be shown that pre-operatively the ratio of errors following ulnar stimulation of a finger to those following radial stimulation is greater in the left hand than in the right, and that this difference is significantly reduced following the operation. It is possible that, in these cases, pre-operatively the side of the finger stimulated, left or right, is being used as a standard of judgment and that post-operatively this dimension of orientation is less prominent. This would be consistent with the results of the data summed for all subjects in so far as they suggest that frames of reference other than the anatomy of the area stimulated may play a role in tactile localization. Orientation in terms of left and right may be such an "external" frame of reference.

\section{Discussion}

The problem of tactile localization has two main aspects which present different but interrelated problems. First, the question may be asked, How much and what type of information is conveyed to the central nervous system? Secondly we may ask, What are the mechanisms of analysis which enable an appropriate localizing response to be made? This is the problem which led Head to postulate a dynamic scheme of orientation which was continuously modified by incoming stimuli. Recognition of the problem of this kind of organization is implicit in the term "body image", a term which, although it has teleological reference, is generally used to connote an unexplored region of neurological function.

It has been shown here that gross errors of tactile localization occur in the absence of neurological lesions, and that following prefrontal leucotomy, 
although the number of errors is increased, the postoperative breakdown of the skill is very similar to the pre-operative error pattern.

It seems likely therefore that our results represent the patterns of weakness inherent in a highly complex skill constituting normal tactile localization rather than an agnosia resulting from a complete deficit of a perceptual function, such as occurs in parietal lesions. Our results suggest that the perceptual responses involved in "local sign" are made in accordance with certain definable dimensions of orientation. Thus, if the distribution of errors is considered as a whole it appears haphazard, but if the errors are considered according to whether the type of error involved is a finger error or a side error the distributions fall into patterns which have obvious conceptual correlates. Thus finger errors increase from the outside of the hand to the inside while side errors occur principally on the ulnar side of the digits, and these ulnar side errors are much more frequent on the radial side of the hand.

Of particular interest is the contingency of the type and direction of error on the site of stimulation. Thus the different distribution on the hands of finger errors and side errors suggests that the subj zct may decide separately which finger and which side of a finger is stimulated. This observation would be difficult to explain as a failure of a directly representational system, and even less consistent with such a theory are the observations concerning the effect of site of stimulus on the direction in which stimuli are erroneously referred. Thus finger errors are displaced mainly in the direction of the side of the finger stimulated, and radial and ulnar displacement of side errors most frequently follow stimulation of fingers on the radial and ulnar sides of the hand respectively. Such results are more consistent with the hypothesis that localizing responses to tactile stimuli are made on the basis of a group of concepts in terms of which such tactile stimuli are organized. According to this theory, when errors occur their location is likely to be determined not only by the adequacy of sensory information but also by the efficiency of interpretation. Moreover, the direction of displacement of errors could be partly determined by a confusion between two frames of reference. Thus, a stimulus on a finger on the ulnar side of the hand would have a quality of " ulnarness" with respect to the side of the hand stimulated, and this quality might wrongly be attributed to the side of the finger stimulated. That is to say, the frame of reference by which the side of the finger stimulated is recognized is contaminated by the frame of reference by which the side of the hand stimulated is recognized. In the same way, a stimulus on the ulnar side of a digit may erroneously be referred towards the ulnar side of the hand, as is also found to occur in our results. In this case, the awareness of "ulnar" stimulation derived from the side of the finger stimulated is attributed to the side of the hand. This kind of effect could be described as the confusion of two dimensions of orientation. "Conceptual contamination" of this type has been observed experimentally, particularly in sorting tests of conceptual thinking or " categorical abstraction ". For example, in Weigl's (McFie and Piercy, 1951) test an organically impaired patient may attempt to sort objects by their shape but the performance may be contaminated by a tendency to sort according to colour at the same time.

In some of our subjects the ratio of errors following ulnar stimulation of a finger to those following radial stimulation is pre-operatively greater in the left hand than in the right. This difference suggests the possibility that the side of the finger, left or right, is also used as a standard of judgment. However, the data is insufficient or the effect too small to stand up to tests of statistical significance in more than two of our subjects. It is noteworthy, however, that the effect is reduced post-operatively. Such an impairment of a dimension of orientation would be consistent with the restriction of perceptual grasp commonly observed in cases of organic brain damage.

Tactile localization on the fingers may thus be regarded as a special instance of the general problem of orientation, and it may be that the orientation of an individual in relation both to his own body and to his external environment depends upon the integrity of a comparatively small number of simply structured dimensions of reference which determine the interpretation placed on incoming stimuli.

\section{Summary}

Tactile localization on the fingers has been studied pre- and post-operatively in patients undergoing prefrontal leucotomy. Although the frequency of gross errors was increased post-operatively similar errors were made before operation, and it was concluded that the operation impaired an imperfect skill in an essentially non-specific manner. The incidence of errors and the direction in which stimuli were erroneously referred were found to depend on the site stimulated. Thus the distribution of errors resulting from the subject's indicating the wrong finger (finger errors) was different from the distribution of errors resulting from the subject's indicating the wrong side of a finger (side errors). 
This suggests that the subject decides separately which finger and which side of a finger is stimulated. Further, the direction of referral of finger errors is positively related to the side of the finger stimulated, and the direction of referral of side errors is similarly related to the side of the hand (ulnar or radial) stimulated. This result has been interpreted as a confusion on the part of the subject between two standards of reference or " concepts", the side of the finger stimulated and the side of the hand stimulated.

These observations are consistent with the hypothesis that normal tactile localization in man occurs through the intermediary of certain dimensions of orientation or concepts. The relevance of these observations to theories of postural orientation and orientation in external space is indicated.
The subjects for this investigation were patients under the care of the physicians and surgeons to the National Hospital, Queen Square, London, and we wish to express our thanks for their permission to study their patients. To Dr. E. Arnold Carmichael, Dr. G. D. Dawson, Dr. Eliot Slater, and Professor O. L. Zangwill we are indebted for criticism and advice.

Malcolm Piercy was supported in this investigation by a grant from the trustees of the Pinsent-Darwin Studentship in Mental Pathology, University of Cambridge.

\section{REFERENCES}

Gerstmann, J. (1924). Wien. klin. Wschr., 37, 1010.

Head, H. (1920). Studies in Neurology, vol. 2. London.

Hulin, W. S. (1935). J. exp. Psychol., 18, 97.

McFie, J., and Piercy, M. (1951). J. ment. Sci., 98, 299.

Sherrington, C. S. (1947). The Integrative Action of the Nervous System, 2nd ed. Cambridge.

Spearman, C. (1906). Psychol. Stud. (Wundt), 1, 388. Walshe, F. M. R. (1942). Brain, 65, 48.

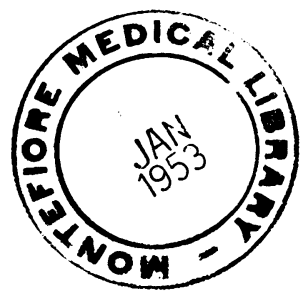

